\title{
Strategi pengembangan lulusan Departemen Manajemen Institut Pertanian Bogor melalui tracer study
}

\author{
Rachmawaty Mochammad SR*, Lindawati Kartika \\ Departemen Manajemen, Fakultas Ekonomi dan Manajemen, Institut Pertanian Bogor \\ *Corresponding Author. e-mail: rachmawaty_239@apps.ipb.ac.id
}

\begin{abstract}
Abstrak
Institut Pertanian Bogor konsisten dalam mempertahankan peringkat universitasnya di tingkat internasional maupun nasional. Lulusan dengan IPK yang baik dan memiliki kompetensi tinggi sangat dibutuhkan dalam memasuki pasar kerja. Tujuan dari penelitian adalah untuk menganalisis hubungan masa tunggu pekerjaan dengan prestasi akademik dan relevansi pekerjaan lulusan Departemen Manajemen IPB. Selain itu juga dilakukan untuk menganalisis aspek pengetahuan dan keterampilan yang menjadi prioritas dalam kebutuhan pekerjaan sekarang dan relevansinya terhadap kompetensi lulusan Departemen Manajemen IPB. Data yang digunakan adalah data primer yang diperoleh melalui kuesioner dan data sekunder dari data akademik Departemen Manajemen IPB. Metode yang digunakan adalah analisis deskriptif, CHAID, IPA dan Net Promoter Score. Lulusan dengan IPK yang baik memiliki masa tunggu pekerjaan cepat dan bidang pekerjaannya memiliki kesesuaian/ relevansi dengan ilmu yang dipelajari. Hasil analisis IPA menunjukkan yang menjadi fokus utama dalam perbaikan kompetensi lulusan Departemen Manajemen IPB adalah kompetensi yang berada pada kuadran concentrate here yaitu pengembangan diri, creativity serta judgement and decision making.
\end{abstract}

Kata kunci: kompetensi, IPA, prestasi akademik, tracer study

\begin{abstract}
IPB University is consistent in maintaning its university rankings at the international and national level. Graduates with a good GPA and a high competence are needed in entering the world of work. Competencies possessed by graduates Department of Management IPB are expected to have conformity with competencies in job requirements. This study examines to: 1) to analyze the relations between work waiting period with academic performance, 2) the relevance of work graduates Department of Management IPB and to analyze aspects of prioritized knowledge and skills in current job needs and their relevance to competency graduating from Department of Management IPB. This research use primary data obtained through questionnaires and secondary from Department of Management IPB. The analytical model used in this study are descriptive analysis, CHAID, IPA and Net Promoter Score. The results of the IPA analysis indicate that the main focus in improving the competence of graduates Department of Management IPB is the competencies that are in the quadrant concentrate here that is self-development, creativity and judgement and decision making.
\end{abstract}

Keywords: competence, IPA, academic achivement, tracer study

How to Cite: Mochammad, R., \& Kartika, L. (2020). Strategi pengembangan lulusan Departemen Manajemen Institut Pertanian Bogor melalui tracer study. FOUNDASIA, 11(1), 1-14. 


\section{PENDAHULUAN}

Pendidikan merupakan fondasi untuk mencapai pertumbuhan masyarakat yang berkualitas dan berkelanjutan. Pendidikan menjadi kunci utama untuk mengikuti perubahan dunia yang dinamis (Silva dan Sá 2018). Sustainable Development Goals (SDGs) atau pembangunan berkelanjutan tidak hanya berurusan dengan masalah lingkungan, tetapi juga masalah ekonomi, sosial budaya dan pendidikan. Pendidikan yang berkualitas merupakan sasaran keempat dari 17 sasaran dalam SDGs yang bertujuan untuk memberdayakan masyarakat dalam mengubah cara berpikir dan bekerja menuju masa depan yang berkelanjutan melalui penerapan pendidikan yang berkualitas baik di setiap tahap kehidupan (Blessinger P. et al. 2018). Pendidikan tinggi berperan dalam menciptakan generasi berkelanjutan yang akan mengambil kepentingan lebih besar karena dunia akan terus mengglobal dan saling tergantung. Institusi pendidikan tinggi dapat membantu mewujudkan SDGs Pendidikan melalui kerjasama dengan staf pengajar, staf pelayanan mahasiswa, mahasiswa aktif, komunitas pemangku kepentingan dan badan lulusan/alumninya (Purcell et al. 2019).

Institusi pendidikan tinggi memiliki peran penting dalam menerapkan dan mengarahkan inisiatif pembangunan berkelanjutan melalui kebijakan dan praktik kelembagaan mereka. Universitas dapat membantu memfasilitasi perubahan menuju masyarakat dunia yang lebih adil dengan mengadopsi SDGs Pendidikan pada tingkat strategis dalam mengejar keberlanjutan dan sebagai cara untuk menghubungkan pendidikan tinggi dengan bisnis, industri, perawatan kesehatan, mitra masyarakat dan pengusaha (Findler, Schönherr, Lozano, Reider, \& Martinuzzi, 2019). Perguruan tinggi merupakan jenjang pendidikan yang sangat penting, karena sumberdaya manusianya disiapkan untuk menghadapi era internet of things (revolusi industri 4.0). Revolusi 4.0 ini sudah memberikan dampak sedemikian besar di dunia, tidak hanya di dunia industri juga dampaknya di dunia pendidikan (Siu, 2002). Empat besar perguruan tinggi Indonesia dengan peringkat internasional tertinggi berdasarkan QS World University Rankings periode tahun 20172019 dapat dilihat pada Tabel 1.

Tabel 1 Empat besar perguruan tinggi Indonesia dengan peringkat internasional tertinggi periode tahun 2017-2019

\begin{tabular}{lccc}
\hline Nama Perguruan Tinggi & $\begin{array}{c}\text { Peringkat } \\
\text { Tahun 2017 }\end{array}$ & $\begin{array}{c}\text { Peringkat } \\
\text { Tahun 2018 }\end{array}$ & $\begin{array}{c}\text { Peringkat } \\
\text { Tahun 2019 }\end{array}$ \\
\hline Universitas Indonesia & 325 & 277 & 296 \\
\hline Universitas Gadjah Mada & $501-550$ & $401-410$ & 320 \\
\hline Institut Teknologi Bandung & $401-410$ & 331 & 331 \\
\hline Institut Pertanian Bogor & 701 & $751-800$ & $601-650$ \\
\hline Sumber: QS World University Rangkings (2019) & &
\end{tabular}

Berdasarkan Tabel 1 mengenai empat besar perguruan tinggi Indonesia dengan peringkat internasional tertinggi periode tahun 2017-2019. Institut Teknologi Bandung, Universitas Gadjah Mada dan Institut Pertanian Bogor mengalami peningkatan rangking setiap tahunnya, sedangkan pada tahun 2019 Universitas Indonesia mengalami penurunan rangking. Peringkat ini dikeluarkan oleh QS World University Rangkings berdasarkan enam aspek evaluasi yaitu academic reputation, employer reputation, faculty/student ratio, citations per faculty, international faculty ratio dan international student ratio. Empat besar perguruan tinggi Indonesia dengan peringkat nasional tertinggi berdasarkan Kementerian Riset, Teknologi dan Perguruan Tinggi (Kemenristekdikti) periode tahun 2017-2019 dapat dilihat pada Tabel 2. 
Tabel 2 Empat besar perguruan tinggi Indonesia dengan peringkat nasional tertinggi periode tahun 2017-2019

\begin{tabular}{lccc}
\hline Nama Perguruan Tinggi & $\begin{array}{c}\text { Peringkat } \\
\mathbf{2 0 1 7}\end{array}$ & $\begin{array}{c}\text { Peringkat } \\
\mathbf{2 0 1 8}\end{array}$ & $\begin{array}{c}\text { Peringkat } \\
\mathbf{2 0 1 9}\end{array}$ \\
\hline Institut Teknologi Bandung & 2 & 1 & 1 \\
\hline Universitas Gadjah Mada & 1 & 2 & 2 \\
\hline Institut Pertanian Bogor & 3 & 3 & 3 \\
\hline Universitas Indonesia & 4 & 4 & 4 \\
\hline
\end{tabular}

Sumber: Kemenristekdikti (2019)

Berdasarkan Tabel 2 mengenai empat besar perguruan tinggi Indonesia dengan peringkat nasional tertinggi periode tahun 2017-2019. Di Indonesia yang menempati peringkat pertama perguruan tinggi terbaik pada tahun 2017 adalah Universitas Gadjah Mada dan pada tahun 20182019 peringkat pertama ditempati oleh Institut Teknologi Bandung. Komponen utama yang digunakan untuk menilai performa perguruan tinggi Indonesia, yaitu kualitas sumberdaya manusia, kualitas kelembagaan, kualitas kegiatan kemahasiswaan, kualitas penelitian dan pengabdian masyarakat serta kualitas inovasi. Berikut adalah perbandingan antara QS World University Rankings dengan Kemenristekdikti mengenai komponen utama yang menjadi aspek evaluasi penentuan rangking universitas tingkat internasional dan nasional dapat dilihat pada Tabel 3.

Tabel 3 Perbandingan komponen utama penentuan rangking universitas antara QS World Rangkings dan Kemeristekdikti

\begin{tabular}{|c|c|c|c|}
\hline \multicolumn{4}{|c|}{ Komponen Utama } \\
\hline $\begin{array}{l}\text { QS World University } \\
\text { Rankings }\end{array}$ & $\begin{array}{l}\text { Proporsi } \\
\text { Penilaian }\end{array}$ & Kemenristekdikti & $\begin{array}{l}\text { Proporsi } \\
\text { Penilaian }\end{array}$ \\
\hline Academic Reputation* & $40 \%$ & $\begin{array}{ll}\text { Kualitas } & \text { Sumberdaya } \\
\text { Manusia*** } & \end{array}$ & $30 \%$ \\
\hline Employer Reputation** & $10 \%$ & Kualitas Kelembagaan* & $30 \%$ \\
\hline Faculty/Student Ratio*** & $20 \%$ & $\begin{array}{ll}\text { Kualitas } & \text { Kegiatan } \\
\text { Kemahasiswaan*** } & \end{array}$ & $10 \%$ \\
\hline Citatios Per Faculty**** & $20 \%$ & $\begin{array}{l}\text { Kualitas Penelitian dan } \\
\text { Pengabdian Masyarakat**** }\end{array}$ & $20 \%$ \\
\hline $\begin{array}{l}\text { International } \\
\text { Ratio } * * *\end{array}$ & $5 \%$ & Kualitas Inovasi** & $10 \%$ \\
\hline $\begin{array}{l}\text { International } \\
\text { Ratio*** }\end{array}$ & $5 \%$ & & \\
\hline
\end{tabular}

Sumber: QS World University Rankings dan Kemenristekdikti (2019)

Keterangan: Komponen penentuan rangking yang serupa ditandai dengan tanda* yang sama.

Berdasarkan Tabel 3 diketahui bahwa penentuan rangking universitas antara QS World University Rangkings dengan Kemeristekdikti memiliki komponen utama yang serupa. Proporsi penilaian pada komponen utama tersebut menjadi faktor penentu Institut Pertanian Bogor konsisten dalam mempertahankan peringkat universitasnya di tingkat internasional maupun nasional. Hal ini menjelaskan bahwa Institut Pertanian Bogor (IPB) secara institusi sudah memiliki kualitas yang baik. Kualitas sumberdaya manusia merupakan salah satu komponen utama yang dapat menjaga kualitas dan mempertahankan peringkat institusi yang diperoleh IPB (Pratama, et al. 2018). Upaya peningkatan kualitas sumberdaya manusia tidak terlepas dari kompetensi mahasiswa dan lulusan itu sendiri.

Program Sarjana Departemen Manajemen merupakan salah satu program studi yang terdapat di Fakultas Ekonomi dan Manajemen Institut Pertanian Bogor (FEM IPB). Departemen Manajemen di lingkungan FEM IPB ditujukan untuk mendukung pencapaian tujuan IPB menjadi perguruan tinggi bertaraf internasional yang memahami konsekuensi globalisasi ekonomi dan lebih tanggap 
terhadap kebutuhan lingkungan dalam menjawab tantangan pengembangan IPTEK dan penyelenggaraan pendidikannya yang lebih berorientasi pada kebutuhan masyarakat. Perubahan dunia kerja di masa yang akan datang bergerak cepat secara sinergis dan berkesinambungan sehingga hampir semua bidang pekerjaan menuntut banyak tenaga kerja profesional yang handal khususnya di bidang manajemen. Bidang manajemen adalah disiplin ilmu yang mengembangkan sumberdaya manusia dengan kompetensi penguasaan ilmu dan keterampilan dalam konteks perorangan dan organisasi (Rafiei dan Davari 2015). Departemen Manajemen IPB mempunyai empat bagian/divisi yang berwenang dalam pengembangan keilmuan yaitu Divisi Manajemen Pemasaran, Manajemen Keuangan, Manajemen Produksi dan Operasi serta Manajemen Sumber Daya Manusia dan Organisasi. Kualitas sumberdaya manusia dapat diketahui melalui angka partisipasi murni (APM) mahasiswa dan kualitas lulusannya. APM digunakan untuk mengetahui seberapa banyak mahasiswa yang memanfaatkan fasilitas pendidikan yang ada (Kemenristekdikti 2017). Keberhasilan seorang mahasiswa tidak hanya diketahui melalui angka partisipasi murni (APM) prestasi non akademik mahasiswa aktif di Departemen Manajemen IPB. Tabel 4 menjelaskan tentang angka partisipasi murni prestasi non-akademik (lokal, nasional dan internasional) yang diperoleh mahasiswa tahun masuk 2015 sampai tahun masuk 2017 Departemen Manajemen IPB sebagai berikut.

Tabel 4 APM prestasi non-akademik mahasiswa Departemen Manajemen IPB

\begin{tabular}{clr}
\hline $\begin{array}{c}\text { Tahun } \\
\text { Masuk }\end{array}$ & Kategori & Rata-rata APM \\
\hline \multirow{3}{*}{2015} & Kompetisi & $20.46 \%$ \\
& Mobilitas & $13.37 \%$ \\
& Arts and Culture & $5.94 \%$ \\
& Sports & $5.94 \%$ \\
& Seminar/Workshop & $88.12 \%$ \\
\hline \multirow{3}{*}{2016} & Kompetisi & $16.22 \%$ \\
& Mobilitas & $9.01 \%$ \\
& Arts and Culture & $9.01 \%$ \\
& Sports & $9.91 \%$ \\
& Seminar/Workshop & $51.35 \%$ \\
\hline \multirow{2}{*}{2017} & Kompetisi & $15.75 \%$ \\
& Mobilitas & $3.54 \%$ \\
& Arts and Culture & $7.09 \%$ \\
& Sports & $7.87 \%$ \\
& Seminar/Workshop & $61.42 \%$ \\
\hline
\end{tabular}

Berdasarkan Tabel 4, menjelaskan tentang rata-rata APM prestasi non-akademik (lokal, nasional dan internasional) mahasiswa Departemen Manajemen IPB. Mahasiswa Departemen Manajemen IPB tahun masuk 2015 memiliki APM prestasi non-akademik yang sangat tinggi dibandingkan dengan mahasiswa Departemen Manajemen IPB tahun masuk yang lainnya. Mahasiswa Departemen Manajemen IPB tahun masuk 2015 merupakan mahasiswa yang ditargetkan lulus pada tahun 2019, artinya rata-rata prestasi non akademik mahasiswa tersebut sudah masuk ke kategori yang baik. Seminar/workshop merupakan prestasi non akademik yang mendapatkan persentasi yang paling besar dari keseluruhan, karena Departemen Manajemen IPB merupakan salah satu Departemen di IPB yang sangat aktif dalam menyelenggarakan seminar/workshop baik secara lokal, nasional maupun internasional dengan penyaji materi yang sudah expert di bidangnya masingmasing.

Kualitas lulusan dapat diketahui melalui studi pelacakan (tracer study). Perguruan tinggi dapat melihat kualitas lulusannya melalui studi penelusuran (tracer study) terhadap lulusannya. Tracer study merupakan studi yang tujuan utamanya untuk memperoleh informasi mengenai lulusan 
yang sudah bekerja dan belum bekerja (Fajaryati et al., 2015). Direktorat Jenderal Pembelajaran dan Kemahasiswaan Kementerian Riset, Teknologi dan Pendidikan Tinggi (Kemenristekdikti) (2018) menjelaskan bahwa tracer study adalah studi pelacakan jejak lulusan yang dilakukan 2 tahun setelah lulus dan bertujuan untuk mengetahui outcome pendidikan dalam bentuk transisi dan dunia pendidikan tinggi ke dunia kerja, situasi kerja terakhir, keselarasan dan aplikasi kompetensi di dunia kerja. Hasil tracer study digunakan sebagai informasi mengenai lulusan untuk dapat memberi umpan balik bagi institusi agar bisa mengevaluasi diri sehingga dapat menyesuaikan dan menyempurnakan kualitas insitusinya (Egesah, 2015). Owusu dan Samuel (2014) menyatakan bahwa tracer study dilakukan untuk menguji seberapa efektif pendidikan yang diterima oleh lulusan untuk menciptakan pekerjaannya sendiri. Hal tersebut menyebabkan institusi pendidikan Departemen Manajemen IPB juga harus mengetahui aspek penting yang dibutuhkan dunia kerja sehingga dapat menciptakan lulusan yang memenuhi kebutuhan tersebut.

Lulusan Departemen Manajemen IPB memiliki kompetensi lulusan yang tidak terbatas karena IPB menerapkan sistem mayor-minor yang mencakup agribisnis, agroindustri, agroservices, dan agrowisata di bidang pertanian, perikanan, kelautan, peternakan, kehutanan, dan kesehatan sehingga lulusan Departemen Manajemen IPB memiliki banyak lapangan kerja yang dapat digeluti. Adhyaksa dan Rusgiyono 2010 menjelaskan bahwa ada beberapa kriteria awal yang dipertimbangkan perusahaan ketika akan merekrut lulusan fresh graduate S1 antara lain seperti indeks prestasi kumulatif, kemampuan bahasa inggris, kesesuaian program studi dengan posisi kerja, nama besar perguruan tinggi, pengalaman magang, pengalaman organisasi, dan lain sebagainya. Keberhasilan prestasi akademik mahasiswa selama mengikuti pendidikan di perguruan tinggi dapat dilihat dari nilai indeks prestasi kumulatif (IPK) dan masa studi (Yogendra dan Andrew 2017).

Indeks prestasi akademik (IPK) merupakan salah satu yang menjadi tolak ukur dalam proses perekrutan pekerjaan, sehingga penting bagi mahasiswa memiliki IPK yang baik (Imose dan Barber 2015). Selain IPK, lama masa studi mahasiswa juga perlu diperhatikan. Lama masa studi yang dibutuhkan lulusan Departemen Manajemen IPB paling cepat 8 semester atau 48 bulan. Rataan IPK dan persentase masa studi lulusan tahun 2014/2015 sampai lulusan tahun 2017/2018 Departemen Manajemen IPB dapat dilihat pada Gambar 1.

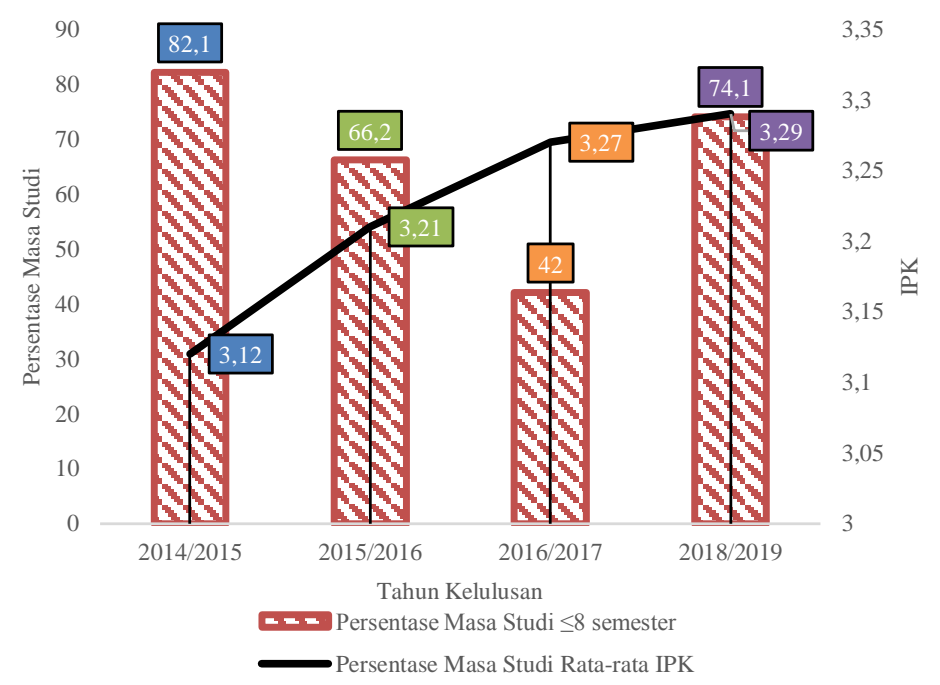

Sumber: Departemen Manajemen IPB (2019)

Gambar 1. Grafik data rataan IPK dan persentase masa studi lulusan tahun 2014/2015 sampai lulusan tahun 2017/2018 Departemen Manajemen IPB

Berdasarkan Gambar 1 bahwa rataan IPK lulusan tahun 2014/2015 sampai lulusan tahun 2017/2018 Departemen Manajemen IPB tergolong sangat baik, karena sudah memenuhi nilai IPK yang dibutuhkan dalam melamar pekerjaan dengan rataan IPK tertinggi terdapat pada lulusan tahun 2017/2018 Departemen Manajemen IPB sebesar 3.29 dan rataan IPK dengan nilai terendah terdapat 
pada lulusan tahun 2014/2015 Departemen Manajemen IPB sebesar 3.12. Sedangkan masa studi lulusan tahun 2014/2015 sampai lulusan tahun 2017/2018 Departemen Manajemen IPB menunjukkan bahwa persentase terbesar lama masa studi lulusan Departemen Manajamen IPB dengan waktu kelulusan $\leq 8$ semester (42-48 bulan) adalah lulusan tahun 2014/2015 sebesar 82.1 persen yang merupakan waktu normal kelulusan di Departemen Manajemen IPB. Sedangkan persentase tertinggi lama masa studi lulusan Departemen Manajemen IPB dengan waktu kelulusan $\geq 8$ semester ( $\geq 48$ bulan) adalah lulusan tahun 2016/2017 sebesar 58 persen. Penyebab lulusan membutuhkan waktu yang lama dalam penyelesaian studinya dikarenakan pemilihan topik tugas akhir yang sulit, jadwal dengan dosen pembimbing yang tidak sesuai serta tuntutan oleh dosen yang perfeksionis juga menjadi penghambat penyelesaian tugas akhir (Tanjung, 2014).

Lulusan dengan prestasi akademik/non akademik yang baik dan waktu masa studi tepat waktu serta memiliki kompetensi tinggi sangat dibutuhkan dalam memasuki pasar kerja. Kompetensi yang dimiliki oleh lulusan Departemen Manajemen IPB diharapkan memiliki kesesuaian dengan kompetensi dalam kebutuhan pekerjaan (Sitepu dan Kehm 2011). Oleh karena itu, Departemen Manajemen IPB perlu memperhatikan IPK dan masa studi serta kesesuaian kompetensi yang dimiliki oleh lulusannya dengan kompetensi yang diperlukan dalam pekerjaan. Informasi mengenai kompetensi yang dimiliki lulusan Departemen Manajemen IPB dapat diketahui melalui studi penelusuran kepada lulusannya agar Departemen Manajemen IPB dapat menilai dan mengevaluasi diri sehingga dapat menyesuaikan dan menyempurnakan akademik agar lebih relevan dengan kebutuhan dunia kerja. Jika lulusan Departemen Manajemen IPB memiliki prestasi akademik dan kompetensi yang baik maka lulusan lebih mudah diterima untuk bekerja dan memiliki masa tunggu pekerjaan yang lebih cepat setelah lulus. Oleh karena itu, penelitian mengenai Strategi Pengembangan Lulusan Departemen Manajemen IPB melalui Tracer Study perlu diadakan.

Pendidikan diyakini sebagai salah satu bidang yang memiliki peran penting dan strategis dalam pembangunan suatu bangsa (Ozturk, 2011). Pendidikan merupakan suatu sistem yang terdiri atas komponen-komponen yang saling terkait secara fungsional bagi tercapainya pendidikan yang berkualitas. Pratama et al. 2018 menjelaskan bahwa proses pendidikan merupakan proses total untuk mengembangkan manusia melalui pendekatan humanisme. Peran tersebut adalah pendidikan berfungsi untuk membina kemanusiaan (human being). Hal ini berarti bahwa pendidikan pada dimaksudkan untuk mengembangkan seluruh pribadi manusia, termasuk mempersiapkan manusia sebagai anggota masyarakat, warga negara yang baik dan rasa persatuan. Pendidikan mempunyai fungsi sebagai human resources yaitu mengembangkan kemampuannya memasuki era kehidupan baru seperti kompetitif dan employability. Sumberdaya yang berkualitas dibentuk melalui peran pendidikan tersebut, sehingga suatu program pendidikan dipersiapkan untuk pengembangan kualitas sumberdaya sesuai dengan transformasi sosial (Patankar dan Jadhav 2013).

Badan Akreditasi Nasional Perguruan Tinggi (BAN-PT) (2019) dalam buku ke V mengenai Instrumen Akreditasi Perguruan Tinggi 4.0 (IAPS 4.0) Program Studi Sarjana menjelaskan bahwa suatu program studi sarjana harus memenuhi beberapa aspek yang menjadi elemen penilaian/parameter sebagai dasar untuk mengukur dan menetapkan mutu kelayakan program studi sarjana untuk menyelenggarakan programnya. Standart penilaian akreditasi kesembilan mengenai luaran dan capaian tridharma pendidikan diukur berdasarkan keberadaan dan implementasi sistem yang menghasilkan data lulusan dan capaian pendidikan yang sahih, mencakup metode yang digunakan untuk mengukur capaian pembelajaran lulusan, prestasi mahasiswa, efektivitas dan produktivitas pendidikan, daya saing lulusan, serta kinerja lulusan. Program studi harus memberikan jaminan mutu, kelayakan kebijakan serta implementasi sistem rekrutmen dan seleksi calon mahasiswa maupun pengelolaan lulusan sebagai satu kesatuan mutu terintegrasi (Da Dalt et al., 2010). Mahasiswa adalah pemangku kepentingan utama internal dan sekaligus sebagai pelaku proses nilai tambah dalam penyelenggaraan akademik yang harus mendapatkan manfaat dari proses pendidikan, penelitian, dan layanan/pengabdian kepada masyarakat. Adapun aspek pengetahuan dan keterampilan yang menjadi elemen penilaian mahasiswa dan lulusan menurut BAN-PT meliputi: Etika (integritas), Keahlian pada bidang ilmu (kompetensi utama), Kemampuan berbahasa asing, Penggunaan teknologi informasi (programming \& technology design), Kemampuan berkomunikasi, Kerjasama dan Pengembangan diri (pengalaman kerja). Berdasarkan IAPS 4.0 (2019) mengenai Panduan Laporan Evaluasi Diri, pemenuhan capaian pembelajaran lulusan yang baik dapat diketahui 
melalui lulusan dengan IPK lebih dari 3.00, lama masa studi yang ditempuh selama $\leq 8$ semester (4248 bulan), masa tunggu pekerjaan $\leq 6$ bulan, dan kesesuaian pekerjaan dan kompetensi yang dimiliki lulusan.

World Economic Forum (2018) menjelaskan bahwa ada 10 aspek keterampilan yang harus dimiliki oleh seorang karyawan di tempat kerja. Aspek ini berguna untuk membuktikan masa depan karir karyawan, guna membangun kompetensi di bidang yang tidak mungkin ditangani mesin secara efektif (yaitu pemecahan masalah kompleks, kreativitas) meliputi: Complex problem solving (Pemecahan masalah kompleks), Critical thinking (Berpikir kritis), Creativity (Kreatifitas), People management (Manajemen orang/manusia), Coordinating with others (Kordinasi dengan orang lain), Emotional intelligence (Kecerdasan emosional), Judgment and decision making (Penilaian dan pengambilan keputusan), Service orientation (Orientasi jasa), Negotiation (Negosiasi) dan Cognitive flexibility (Kecerdasan dalam bertindak).

\section{METODE PENELITIAN}

Metode yang digunakan adalah analisis deskriptif, CHAID, IPA dan Net Promoter Score. Data yang digunakan adalah data primer yang diperoleh melalui kuesioner dan data sekunder dari data akademik Departemen Manajemen IPB. Perbedaan penelitian ini dengan penelitian terdahulu terletak pada objek yang akan diteliti dan variabel yang digunakan. Penelitian ini mengambil objek lulusan Departemen Manajemen IPB dimana fokus utama penelitian ini adalah terkait kompetensi lulusan yang dibutuhkan dalam pasar kerja. Hal tersebut tidak dilakukan pada penelitian-penelitian terdahulu yang hanya berfokus pada prestasi akademik mahasiswa.

\section{HASIL DAN PEMBAHASAN}

\section{Karakteristik Responden Lulusan Departemen Manajemen IPB}

Responden dalam penelitian ini sebanyak 220 orang responden yang berasal dari lulusan Departemen Manajemen IPB sebanyak 4 angkatan yakni lulusan tahun 2014/2015 sampai dengan lulusan tahun 2017/2018. Karakteristik lulusan Departemen Manajemen IPB sebagian besar merupakan perempuan dengan jumlah 63.2 persen dari total keseluruhan responden. IPK dan masa studi yang dimiliki lulusan Departemen Manajemen IPB cenderung berada peringkat sangat baik yaitu lebih dari 3.00 dan lama masa studi yang ditempuh dalam kurun waktu $>42-48$ bulan (BAN PT 2019). Sebanyak 36.8 persen dan 33.2 persen lulusan Departemen Manajemen IPB yang memiliki IPK >3.00-3.50 dan >3.50-4.00. Sedangkan masa studi lulusan Departemen Manajemen IPB pada kurun waktu $>42-48$ bulan sebanyak 66.8 persen. Pada umumnya lulusan Departemen Manajemen IPB langsung mencari pekerjaan setelah lulus dari Departemen Manajemen IPB, sehingga masa tunggu pekerjaan pertama lulusannya kurang dari 6 bulan sebanyak 71.8 persen. Lulusan Departemen Manajemen IPB memiliki bidang pekerjaan yang sesuai dengan bidang ilmu manajemen yang dipelajari di Departemen Manajemen IPB sebanyak 76.8 persen. Sebanyak 13.2 persen lulusan Departemen Manajemen IPB tidak memiliki pekerjaan dikarenakan baru menyelesaikan studinya di Departemen Manajemen IPB, ada yang melanjutkan pendidikannya ke jenjang pascasarjana serta pernah memiliki pekerjaan tetapi berhenti karena urusan pribadi.

\section{Hubungan Masa Tunggu Pekerjaan dengan IPK dan Kesesuaian Pekerjaan dengan Ilmu yang Dipelajari Lulusan di Departemen Manajemen IPB}

Analisis dengan metode CHAID digunakan untuk melihat hubungan antara masa tunggu pekerjaan dengan IPK lulusan Departemen Manajemen IPB. Hasil analisis metode CHAID dari variabel dependen dan variabel independen yang berhubungan membentuk diagram pohon CHAID (Wirania et al. 2013). Adapun hasil analisis masa tunggu pekerjaan dengan IPK lulusan Departemen Manajemen IPB dapat dilihat pada Gambar 4. 


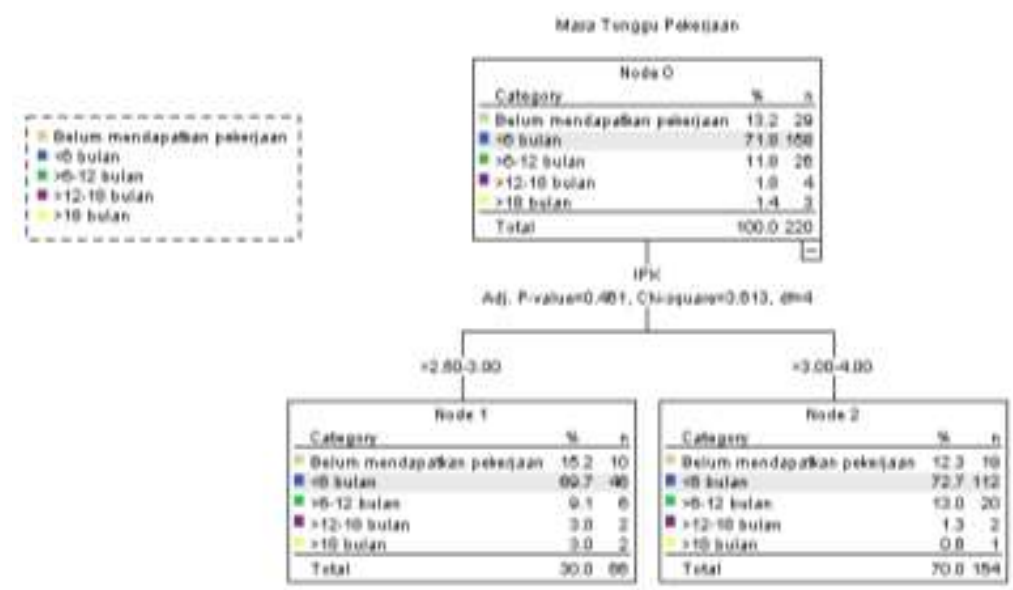

Gambar 2. Diagram pohon CHAID analisis hubungan masa tunggu pekerjaan dengan prestasi akademik (IPK) lulusan Departemen Manajemen IPB

Gambar 2 menunjukkan hubungan masa tunggu pekerjaan dengan prestasi akademik. Lulusan Departemen Manajemen IPB yang memiliki IPK $>2.50-3.00$ dan $>3.00-4.00$ pada umumnya memiliki masa tunggu pekerjaan $<6$ bulan. Hal ini menunjukkan bahwa penyerapan lulusan Departemen Manajemen IPB di pasar kerja sangat baik dan pekerjaannya memiliki kesesuaian dengan ilmu yang dipelajari di Departemen Manajemen IPB. Sebanyak 29 lulusan yang belum memiliki pekerjaan dikarenakan ada yang baru menyelesaikan studi di Departemen Manajemen dan sedang mencari pekerjaan, serta ada pula yang belum memiliki pekerjaan dikarenakan melanjutkan studi ke jenjang pascasarjana. Berikut hasil tabulasi silang yang menunjukkan lulusan yang memiliki IPK >2.50-3.00 dan >3.00-4.00 dengan masa tunggu pekerjaan $<6$ bulan dan memiliki kesesuaian pekerjaan dengan ilmu yang dipelajari lulusan di Departemen Manajemen IPB disajikan pada Tabel 5.

Tabel 5 Tabulasi silang IPK dengan masa tunggu pekerjaan dan kesesuaian pekerjaan dengan ilmu yang dipelajari lulusan

\begin{tabular}{|c|c|c|c|c|}
\hline \multirow{2}{*}{\multicolumn{3}{|c|}{ Tabulasi Silang }} & $\begin{array}{l}\text { Masa Tunggu } \\
\text { Pekerjaan }\end{array}$ & Kesesuaian Pekerjaan \\
\hline & & & $\leq 6$ bulan & Sesuai \\
\hline \multirow{4}{*}{ IPK } & $>2.50$ & Jumlah & 46 & 54 \\
\hline & 3.00 & Persentase & $69.7 \%$ & $81.2 \%$ \\
\hline & $>3.00$ & Jumlah & 112 & 115 \\
\hline & 4.00 & Persentase & $72.7 \%$ & $74.7 \%$ \\
\hline \multirow{2}{*}{ Total } & & Jumlah & 158 & 169 \\
\hline & & Persentase & $71.8 \%$ & $76.8 \%$ \\
\hline
\end{tabular}

Berdasarkan hasil analisis tabulasi silang IPK dengan masa tunggu pekerjaan dan kesesuaian pekerjaan dengan ilmu yang dipelajari di Departemen Manajemen IPB lulusan dengan IPK > 2.503.00 memiliki masa tunggu pekerjaan kurang dari 6 bulan sebanyak 46 orang dengan jenis institusi pekerjaan yaitu perusahaan swasta, mempunyai bisnis sendiri dan bekerja sebagai honorer. Sedangkan lulusan dengan IPK >3.00-4.00 dengan masa tunggu pekerjaan kurang dari 6 bulan sebanyak 112 orang memiliki jenis institusi pekerjaan yaitu perusahaan nasional, BUMN dan juga memiliki bisnis sendiri. Sebanyak 169 orang mempunyai bidang pekerjaan yang sesuai dengan ilmu yang dipelajarinya selama menempuh pendidikan di Departemen Manajemen IPB.

Aspek Pengetahuan dan Keterampilan dalam Relevansi kompetensi lulusan Departemen Manajemen IPB dan kebutuhan perusahaan dalam pekerjaan sekarang 
Kompetensi yang dimiliki oleh lulusan akan berbeda dengan kompetensi yang dibutuhkan dalam kebutuhan perusahaan dalam pekerjaan. Kompetensi mengacu pada pengetahuan, keterampilan, kemampuan atau karakteristik kepribadian individual yang secara langsung mempengaruhi kinerja (Becker et al. 2001). Hasil analisis IPA digunakan untuk membandingkan aspek pengetahuan dan keterampilan berdasarkan BAN-PT 2019 dan WEF 2018 yang digambarkan melalui diagram kartesius. Adapun hasil analisis diagram berdasarkan standart BAN-PT 2019 dapat dilihat pada Gambar 3.

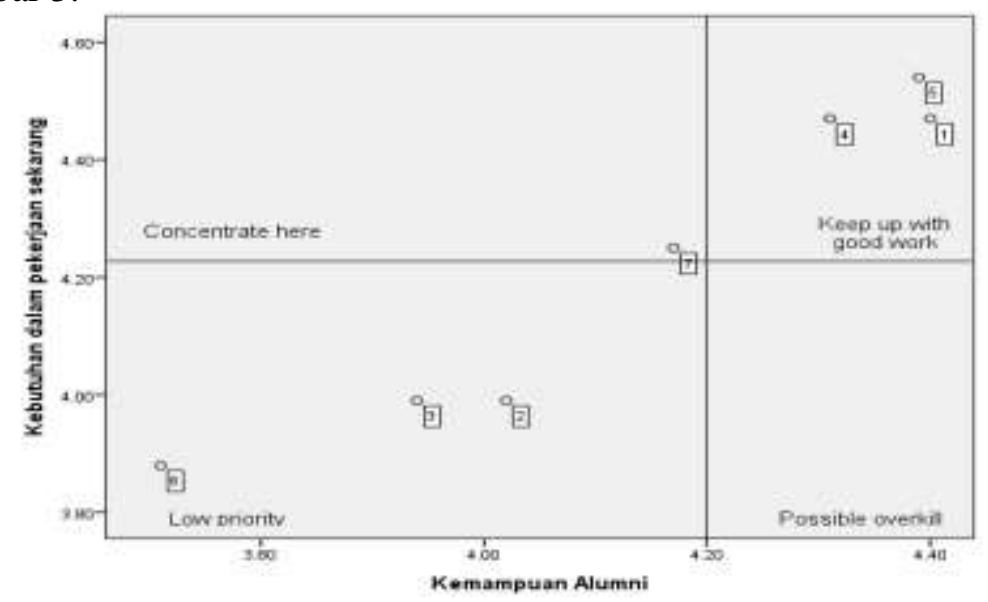

Gambar 3 Hasil model IPA 1 (BAN-PT 2019) Gambar 4.

Selanjutnya hasil analisis diagram kartesius berdasarkan WEF 2018 dapat dilihat pada

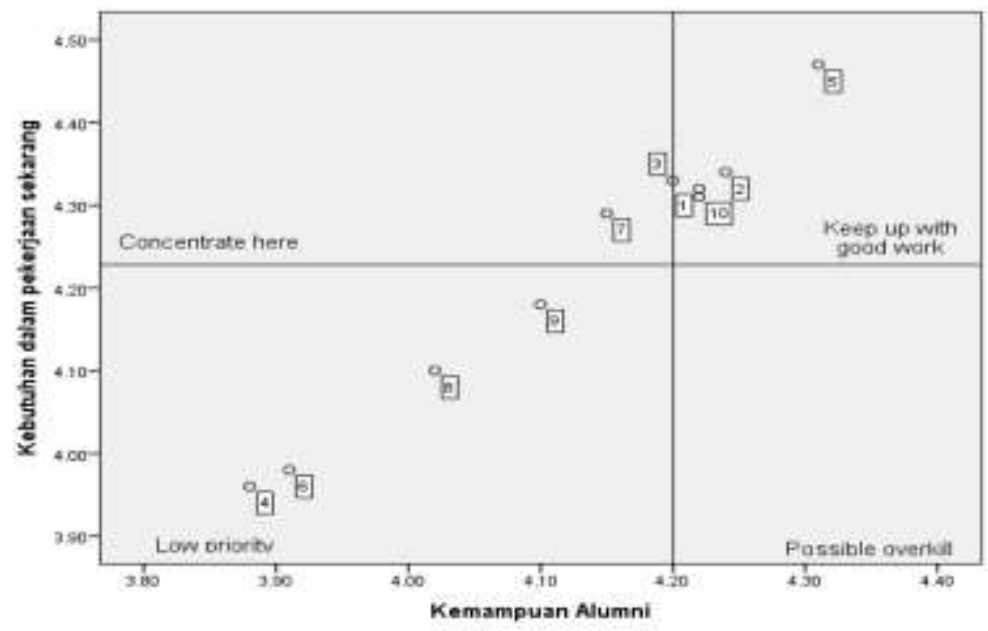

Gambar 4 Hasil model IPA 2 (WEF 2018)

Hasil diagram kartesius merupakan 7 aspek pengetahuan dan keterampilan berdasarkan standart BAN-PT 2019 dan 10 aspek pengetahuan dan keterampilan berdasarkan WEF 2018 yang menjadi prioritas dalam kebutuhan pekerjaan sekarang dan relevansinya terhadap kompetensi lulusan Departemen Manajemen IPB dapat dilihat pada Tabel 6.

Tabel 6 Hasil diagram kartesius 


\begin{tabular}{|c|c|c|}
\hline \multirow[t]{2}{*}{ Kuadran } & $\begin{array}{c}\text { Hasil model IPA } 1 \\
\text { (BAN-PT 2019) }\end{array}$ & $\begin{array}{l}\text { Hasil model IPA } 2 \\
\text { (WEF 2018) }\end{array}$ \\
\hline & Aspek & Aspek \\
\hline Concentrate here & 7. Pengembangan diri & $\begin{array}{l}\text { 3. Creativity } \\
\text { 7. Judgment and Decision } \\
\text { Making }\end{array}$ \\
\hline $\begin{array}{l}\text { Keep up with good } \\
\text { work }\end{array}$ & $\begin{array}{l}\text { 1. Etika (Integritas) } \\
\text { 5. Kemampuan berkomunikasi } \\
\text { 4.Penggunaan teknologi dan } \\
\text { informasi }\end{array}$ & $\begin{array}{l}\text { 5. Coordinating with Others } \\
\text { 2. Critical thingking } \\
\text { 10. Cognitive Flexibility } \\
\text { 1. Complex problem solving }\end{array}$ \\
\hline Low priority & $\begin{array}{l}\text { 2. Keahlian pada bidang ilmu } \\
\text { 3. Kemampuan berbahasa asing } \\
\text { 6. Kerjasama }\end{array}$ & $\begin{array}{l}\text { 9. Negotiation } \\
\text { 8. Service Orientation } \\
\text { 6. Emotional Intelligence } \\
\text { 4. People Management. }\end{array}$ \\
\hline Possible overkill & - & - \\
\hline
\end{tabular}

Tabel 6 menjelaskan hasil perbandingan dari hasil model IPA 1 dan hasil model IPA 2. Standart penilaian BAN-PT 2019 sebagai acuan keuggulan mutu mahasiswa dan lulusan. Program studi harus memberikan jaminan mutu, kelayakan kebijakan serta implementasi sistem rekrutmen dan seleksi calon mahasiswa maupun pengelolaan lulusan sebagai satu kesatuan mutu terintegrasi. Pada hasil model IPA 1 yang masuk ke dalam kuadran concentrate here adalah pengembangan diri artinya kompetensi yang dimiliki oleh lulusan Departemen Manajemen IPB pada aspek ini masih dalam kondisi yang belum memuaskan akan tetapi dalam kebutuhan pekerjaan merupakan aspek yang penting sehingga perlu ditingkatkan lagi. Pada kuadran keep up with the good work terdapat tiga aspek kompetensi yaitu etika (integritas), kemampuan berkomunikasi dan penggunaan teknologi dan informasi artinya kompetensi yang dimiliki oleh lulusan Departemen Manajemen IPB sudah sesuai dengan kebutuhan perusahaan dalam pekerjaan sekarang. Aspek kompetensi yang terdapat pada kuadran ini dianggap sebagai kondisi yang sudah memuaskan dan perlu dipertahankan untuk mempertahankan prestasi yang dicapai oleh lulusan Departemen Manajemen IPB. Terakhir, terdapat tiga aspek yang masuk pada kuadran low priority yaitu keahlian pada bidang ilmu, kemampuan berbahasa asing dan kerjasama artinya aspek kompetensi ini dianggap sebagai tingkat kepentingan yang rendah terhadap kompetensi yang dimiliki oleh lulusan Departemen Manajemen IPB sehingga tidak terlalu di prioritaskan didalam kebutuhan pekerjaan sekarang.

Aspek yang termasuk ke dalam WEF 2018 berguna untuk membuktikan masa depan karir karyawan, guna membangun kompetensi di bidang yang tidak mungkin ditangani mesin secara efektif. Hasil model IPA 2 yang masuk ke dalam kuadran concentrate here yaitu creativity dan judgment and decision making yang berarti pada aspek ini kompetensi yang dimiliki oleh lulusan Departemen Manajemen IPB masih dalam kondisi yang belum memuaskan akan tetapi dalam kebutuhan pekerjaan merupakan aspek yang penting sehingga aspek yang terdapat pada kuadran ini perlu ditingkatkan lagi. Pada kuadran keep up with the good work terdapat empat aspek kompetensi yaitu coordinating with others, cognitive flexibility, critical thinking dan complex problem solving dan artinya kompetensi yang dimiliki oleh lulusan Departemen Manajemen IPB sudah sesuai dengan kebutuhan perusahaan dengan kebutuhan perusahaan dalam pekerjaan sekarang. Aspek kompetensi yang terdapat pada kuadran ini dianggap sebagai kondisi yang sudah memuaskan dan perlu dipertahankan untuk mempertahankan prestasi yang dicapai oleh lulusan Departemen Manajemen IPB. Terakhir, terdapat empat aspek yang masuk pada kuadran low priority yaitu negotiation, service orientation, emotional intelligence dan people management artinya aspek kompetensi ini dianggap sebagai tingkat kepentingan yang rendah terhadap kompetensi yang dimiliki oleh lulusan Departemen Manajemen IPB sehingga tidak terlalu di prioritaskan didalam kebutuhan pekerjaan sekarang.

Variabel-variabel yang masuk ke dalam kuadran concentrate here model IPA 1 (BAN-PT) dan model IPA 2 (WEF 2018) merupakan kompetensi yang dianggap kurang memuaskan sehingga diperlukan peningkatan kompetensi tersebut melalui Strategic Initiative IPB 4.0 dan Kegiatankegiatan Kemahasiswaan yang ada di IPB. Strategic Initiative IPB 4.0 merupakan strategi yang akan 
dilakukan oleh IPB agar dapat beradaptasi cepat di era revolusi industri 4.0 dalam upaya menghasilkan lulusan yang mampu bersaing dan berperan di era revolusi industri 4.0. Selain itu, keikutsertaan dalam kegiatan-kegiatan kemahasiswaan yang ada di IPB dapat membantu dalam proses peningkatan kompetensi yang dimiliki oleh lulusan/mahasiswa Departemen Manajemen IPB.

\section{Net Promoter Score}

Penelitian ini menggunakan metode NPS untuk melihat loyalitas dari lulusan Departemen Manajemen IPB. Hasil dari NPS ini diharapkan akan bermanfaat bagi Departemen Manajemen IPB sebagai sebuah institusi pendidikan untuk senantiasa meningkatkan dan memperbaiki kualitasnya. Berikut klasifikasi responden untuk net promoter score pada Tabel 7.

Tabel 7. Klasifikasi responden untuk Net Promoter Score

\begin{tabular}{lcl}
\hline Jenis & Jumlah (orang) & Persentase (\%) \\
\hline Promoters & 78 & 35.5 \\
Passives & 117 & 53.2 \\
Detractors & 25 & 11.4 \\
\hline Total & 208 & 100 \\
\hline
\end{tabular}

Perhitungan NPS adalah persentase promoters dikurang dengan persentase detractors. Berdasarkan tabel di atas maka nilai NPS yang diperoleh Departemen Manajemen IPB adalah 24.1 persen. Berdasarkan data di atas, Departemen Manajemen IPB masih harus meningkatkan kualitasnya, hal ini ditunjukkan oleh data responden dengan kriteria passives masih cukup besar di angka 52.2 persen. Kriteria passives merupakan orang belum memiliki kecondongan untuk menjadi promoters atau detractors. Apabila kualitas Departemen Manajemen IPB meningkat maka kriteria passives bisa diarahkan untuk masuk ke dalam kriteria promoters. Sejumlah 25 orang atau 12 persen lulusan Departemen Manajemen IPB yang termasuk ke dalam kriteria detractors dan alasannya yang dapat dilihat pada Gambar 5.

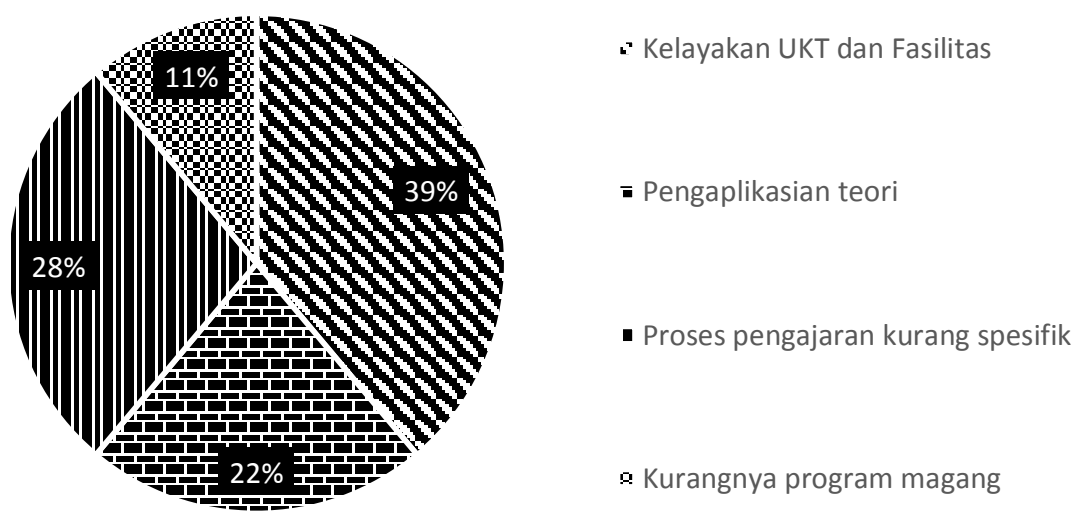

Gambar 5 Responden yang termasuk ke dalam kriteria detractors dan alasannya

Berdasarkan Gambar 5 mengenai alasan yang menjadikan lulusan Departemen Manajemen IPB masuk ke kriteria detractors dikarenakan oleh besaran uang kuliah tunggal (UKT) yang ada dengan fasilitas yang didapatkan masih belum sesuai, kurangnya pengaplikasian teori dari beberapa mata kuliah, proses pengajaran yang dianggap kurang spesifik sehingga tidak memiliki konsep yang kuat sehingga dibutuhkan penambahan materi baru sehingga bisa menyesuaikan dengan kebutuhan pekerjaan yang sekarang. Departemen Manajemen IPB dapat melakukan penambahan materi juga pengaplikasiannya secara langsung baik berupa guest lecturer ataupun menambah kelas responsi dengan melakukan simulasi nyata untuk materi tersebut. Penambahan materi praktikal untuk 
Manajemen Sumberdaya Manusia berupa communication skills, recruitment process/wawancara, debat negosiasi, public speaking, design thinking. Manajemen Pemasaran dapat melakukan penambahan materi secara teori mengenai digital marketing, marketing intelligent, consumer insight, perencanaan bisnis dan business communication. Manajemen Keuangan berupa penambahan materi ilmu perpajakan, tata kelola administrasi, serta aktuaria. Manajemen Produksi Operasi berupa pendalaman materi manajemen gudang/stok, manajemen proyek dan manajemen logistik/perhotelan. Selain itu, pelaksaan program internship/magang sangat dibutuhkan oleh mahasiswa Departemen Manajemen IPB sebagai penunjang kebutuhan di dunia kerja mahasiswa.

\section{SIMPULAN}

Simpulan yang diperoleh dari hasil penelitian ini adalah sebagai berikut: Mayoritas lulusan Departemen Manajemen IPB merupakan perempuan. Lulusan Departemen Manajemen IPB memiliki IPK yang sangat baik dan lama masa studi tepat waktu selama empat tahun atau delapan semester. Setelah lulus dari Departemen Manajemen IPB mayoritas lulusan langsung mencari pekerjaan dengan masa tunggu pekerjaan pertama kurang dari enam bulan yang rata-rata bidang pekerjaannya sesuai dengan bidang ilmu manajemen yang dipelajari di Departemen Manajemen IPB: Lulusan Departemen Manajemen IPB yang memiliki IPK di atas dua koma lima sampai empat pada umumnya memiliki masa tunggu pekerjaan kurang dari enam bulan dan bidang pekerjaannya memiliki kesesuaian/relevansi dengan ilmu yang dipelajari di Departemen Manajemen IPB; Departemen Manajemen IPB mengharapkan semua lulusannya memiliki kompetensi di dunia kerja berada pada kriteria baik/sangat baik, sehingga kompetensi lulusan Departemen Manajemen IPB yang perlu menjadi fokus utama perbaikan adalah kompetensi yang berada pada kuadran concentrate here yaitu pengembangan diri, creativity serta judgement and decision making; Hanya 35.5 persen lulusan Departemen Manajemen IPB yang berperan sebagai promoter terhadap Departemen Manajemen IPB. Berdasarkan hasil perhitungan dan pembahasan dari Net Promoter Score dan hasil dari model IPA 1 dan model IPA 2. Departemen Manajemen IPB harus melakukan perbaikan untuk meningkatkan kualitas pendidikannya untuk aspek pengetahuan dan keterampilan yang berada pada kuadran concentrate here yaitu pengembangan diri, creativity serta judgement and decision making.

Saran dari hasil penelitian ini adalah sebagai berikut: Departemen Manajemen IPB perlu melakukan penambahan materi perkuliahan yang spesifik sesuai dengan hasil NPS kategori detractors di bidang manajemen sumberdaya manusia, manajemen pemasaran, manajemen keungan dan manajemen produksi operasi; Peneliti selanjutnya disarankan untuk melakukan penelitian berkelanjutan berdasarkan hasil penelitian ini seperti meneliti kesesuaian bidang peminatan skripsi dengan bidang kerja serta faktor-faktor yang mempengaruhi lulusan Departemen Manajemen IPB memiliki masa tunggu pekerjaan yang cepat.

\section{DAFTAR PUSTAKA}

Adhyaksa, M. Atma, and Agus Rusgiyono. (2010). Persepsi dunia kerja terhadap lulusan fresh graduate s1 menggunakan multidimensional unfolding (studi kasus: dunia usaha di kabupaten batang). Media Statistika. 3 (1): 49-57.

[BAN-PT] Badan Akreditasi Nasional Perguruan Tinggi. (2019). Instrumen Akreditasi Program 4.0 (IAPS 4.0) Buku ke V. Jakarta (ID): BAN-PT.

Becker BE, Huselid MA, Ulrich D. (2001). The HR Scorecard: Linking People, Strategy and Performance. United States of America: President and Fellows of Harvard College. [Internet]. [diunduh $2019 \quad$ Mei 18]; 23(10):1-8. Tersedia pada: http://www.businesstraining.com.mx/egaii/docs/ The\%20HR\% 20Scorecad.pdf.

Blessinger P, Sengupta E, Mandla. (2018). Higher education's key role in sustainable development [internet]. [diakses pada 2019 Jul 7]. Tersedia pada: https://www.universityworldnews.com/post.php?story=20180905082834986

Dalt, Liviana Da, Silvia Callegaro, Anna Mazzi, Antonio Scipioni, Paola Lago, Maria L. Chiozza, Franco Zacchello, and Giorgio Perilongo. (2010). A model of quality assurance and quality improvement for post-graduate medical education in Europe. Medical Teacher. 32 (2). DOI: 
https://doi.org/10.3109/01421590903199734.

Egesah, Omar. (2015). University graduate tracer studies (unitrace): methodological lessons and utilization of selected results in Kenya. Journal Of International Academic Research For Multidisciplinary. 2(8): 305-325.

Fajaryati, Nuryake, Totok Sukardiyono, Athika Dwi, Wiji Utami, Sigit Pambudi, and Bonita Destiana. (2015). Studi penelusuran ( tracer study) terhadap alumni program studi pendidikan teknik informatika jurusan. Jurnal Electronics, Informatics, and Vocational Education. 1: 23148.

Findler, Florian, Norma Schönherr, Rodrigo Lozano, Daniela Reider, and André Martinuzzi. (2019). The impacts of higher education institutions on sustainable development: a review and conceptualization. International Journal of Sustainability in Higher Education. 20 (1): 23-38. DOI: https://doi.org/10.1108/IJSHE-07-2017-0114.

Imose, Ruth, and Larissa K. Barber. (2015). Using undergraduate grade point average as a selection tool: a synthesis of the literature. Psychologist-Manager Journal 18 (1): 1-11. DOI: https://doi.org/10.1037/mgr0000025.

[Kemenristekdikti] Kementerian Riset, Teknologi, dan Pendidikan Tinggi. (2018). Panduan Bantuan Pusat Karir Lanjutan 2018 [internet]. [diakses pada 2019 Apr 4]. Tersedia pada: http://pkts.belmawa.ristekdikti.go.id/upload/1518248656_panduan_bantuan\%20pusat\%20ka rir\%20lanjutan_2018.pdf

[Kemenristekdikti] Kementerian Riset, Teknologi, dan Pendidikan Tinggi. (2019). Peringkat Perguruan Tinggi di Indonesia 2018 [internet]. [diakses pada 2019 Jul 18]. Tersedia pada: https://ristekdikti.go.id/kabar/kemenristekdikti-umumkan-peringkat-100-besar-perguruantinggi-indonesia-non-vokasi-tahun-2018/

[Kemenristekdikti] Kementerian Riset, Teknologi, dan Pendidikan Tinggi. (2017). Laporan Kinerja Kemenristekdikti [internet]. [diunduh pada 2019 Jul 18]. Tersedia pada: https://ristekdikti.go.id/wp-content/uploads/2018/08/LAPORAN-KINERJAKEMENRISTEKDIKTI-2017.pdf

Owusu-Mintah, Samuel B. (2014). Entrepreneurship education and job creation for tourism graduates in ghana. Education and Training. 56: 826-38. DOI: https://doi.org/10.1108/ET-012014-0001.

Ozturk, Ilhan. (2011). The role of education in economic development: a theoretical perspective. SSRN Electronic Journal. 33(1): 39-47. DOI: https://doi.org/10.2139/ssrn.1137541.

Patankar Pratibha S, Jadhav Megha Sahebrao. (2013). Role of teachers' in curriculum development for teacher role of teachers ' in curriculum development for teacher education. National Conference [internet]. [diunduh pada 2019 Jul 17]. Tersedia pada: https://www.researchgate.net/publication/258023165

Pratama Rahardian Okta, Kartika Lindawati, Sayekti Andita. (2018). Analisis faktor-faktor yang memengaruhi prestasi. 32 (2): 153-63. Tersedia pada: http://journal.unj.ac.id/unj/index.php/pip/article/view/7763.

Purcell, Wendy Maria, Heather Henriksen, and John D. Spengler. (2019). Universities as the engine of transformational sustainability toward delivering the sustainable development goals: 'living labs' for sustainability. International Journal of Sustainability in Higher Education. DOI: https://doi.org/10.1108/IJSHE-02-2019-0103.

[QS] QS World University Rangkings. (2019). World University Rangkings 2020 [internet]. [diakses pada 2019 Apr 18]. Tersedia pada: https://www.topuniversities.com/universityrankings/world-university-rankings/2020

Rafiei Nafiseh, Fereshte Davari. (2015). The role of human resources management on enhancing the 
teaching skills of faculty members. Materia Socio Medica. 27 (1): 35. DOI: https://doi.org/10.5455/msm.2014.27.35-38.

Silva, Elizabeth, and Artur A. Sá. (2018). Educational challenges in the portuguese unesco global geoparks: contributing for the implementation of the SDG 4. International Journal of Geoheritage and Parks. 6 (1): 95-106. DOI: https://doi.org/10.17149/IJG.J.ISSN.2210.3382.2018.01.007.

Sitepu Ied V R, Prof. Dr. Barbara M Kehm. (2011). Competencies of higher education graduates: A case of Universitas Kristen Indonesia [Disertasi]. Jerman (DEU): University of Kassel.

Siu, K.W.M. 2002. "Impact of new technology on teaching and learning in technology education: opportunity or threat?" Design and Technology Associationn International Research Conference, 12-14 April 2002, 29-37. https://core.ac.uk/download/pdf/2739241.pdf.

[WEF] World Economic Forum. (2018). 10 skilss you'll need to survive the rise of automation [internet]. [diakses pada 2019 Mar 10]. Tersedia pada: https://www.weforum.org/agenda/2018/07/the-skills-needed-to-survive-the-robot-invasionof-the-workplace

Wirania Y, Mara MN, Kusnandar D. (2013). Pembentukan Pohon Klasifikasi dengan Metode CHAID. Buletin Ilmiah Mat. Stat. dan Terapannya (Bimaster). 2(1):45-50.

Yogendra, Nirogini, and Anthony Andrew. (2017). A study on the factors influencing on grade point average (gpa) with special reference to third year commerce and management students of eastern university, Sri Lanka. Journal for Studies in Management and Planning. 3 (8): 409-25. 